Send your letters to the Editor, British Dental Journal, 64 Wimpole Street, London W1G 8YS. E-mail bdj@bda-dentistry.org.uk Priority will be given to letters less than 500 words long. Authors must sign the letter, which may be edited for reasons of space.

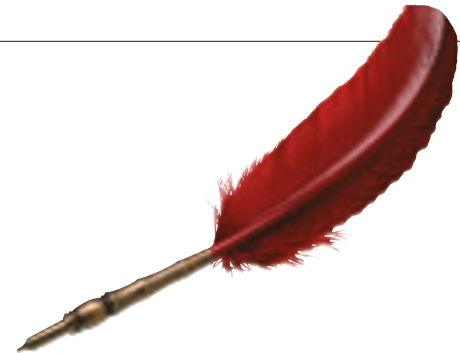

iii) Protection against introduction of micro organisms into the open cavity. This is a theoretical problem which no more applies to endodontics, than to any other type of operative dentistry. Is there any evidence that any procedure carried under rubber dam is more successful?

iv) Improved access/vision for operator. This is just personal reference. There are also disadvantages with the use of rubber dam, which includes patient discomfort, soft tissue damage and accidental tooth fracture.

I would very much like to learn if I have failed to consider any crucial points.

\section{J. R. Mackay}

Chalfont St. Peter ciable quantity of mercury was released from two carriers after approximately three weeks service.

I am writing in order to draw dentists attention to this problem - these carriers had been through numerous autoclave cycles with the attendant risk of mercury vapour release. We are fortunate that the autoclaves are situated in an area of the practice which is well ventilated and where staff or patients do not spend any appreciable time - but the situation could have been more damaging had the autoclaves been located within a surgery.

There has been recent publicity about the risk of mercury being released from amalgam capsules, matrix bands and the like - it would seem to me that the risk posed by mercury retained within amalgam carriers is of equal importance and we should all be ensuring that each

\section{Rubber dam in endodontics}

Sir, - It is rapidly becoming accepted wisdom that the use of rubber dam is essential when carrying out endodontic treatment. It seems to me that we are moving towards a situation where failure to use rubber dam could be seen as negligent. I am not convinced that this somewhat intolerant view is justified, and have dealt with the points usually sighted to support it.

i) Protection for patient against inhalation or ingestion of a dropped

\section{Gingival recession}

Sir, - I was interested to see the article by J. J. O'Dwyer and A. Holmes showing gingival recession due to a lip stud. The clinical picture is very similar to that seen where there are crowded lower incisors, where one lower incisor is labially displaced.

The probable reason in both cases, is that pressure from the lower lip against the labial bone induces osteoclasis and the resultant gingival recession. In the case of the lip stud, the artificial lump of metal exerts localised pressure against the bone labial to the incisor. I suspect that if the lower incisors had been spaced the tooth in question would have moved lingually and there would have been no recession of the gingivae.

\section{R. T. Broadway.}

\section{Winchester}

\section{instrument.}

True, if hand files are used without a safety chain, then rubber dam is a good idea. However, my own canal preparation technique involves using giromatic files to establish a patient canal.

ii) Protection for patient against unpleasant taste/toxicity of sodium hypochloride. This is not a problem with efficient aspiration. In fact, I have actually experienced more problems in this respect with rubber dam on, due to leakage around the clamp.

\section{Practice of UK dentistry}

Sir, - Recently in the BDJ and GDPA Journal there has been considerable correspondence about the proposed, but inevitable, increase in the GDC

Registration fee. It would seem that the profession, as a whole, is impotent yet again to do anything to prevent its taking effect. I wonder how many colleagues will be removing their name from the Register because they are unable to practice and have retired on medical 
grounds, and that the increase in the fee and the financial demands of CPD are prohibitive on a limited income. Presumably this will mean a reduction in the overall income to the GDC.

As there are major upheavals of this sort now about to occur, maybe we should be looking realistically and radically at the practice of dentistry in the UK. Is it not time for the profession to say enough is enough? If Government really does want a 'National Health Service' maybe this should be provided by employed dentists in totally NHS Centres.

If the success of the Access Centres is to be believed surely this is a pragmatic option, always assuming, of course, that the dentists working in those centres are paid a viable salary in line with consultants and have a defined career pathway. This would then free up general dental practices to provide realistically funded services to the very highest standards.

of course it might be possible for Government to ‘buy-in' from general dental practice at commercially competitive rates. It might also make the mandarins realise the full complexity of dental practice and its financial implications. After all, the Access Centre dentist appears to treat as many patients in a full week as the average high street practitioner does in one day!

Joe Sullivan suggests in the leader of the GDP of June 2002 that the official figures equate to $£ 266$ being the cost of treating each patient. Perhaps this should be the basis for funding the new arrangements?

\section{N. R. Winter \\ Sevenoaks}

\section{Access to the GDS}

Sir, - P. Howard-Williams makes many excellent points about the debate regarding funding and access to the GDS. However, I think he is unrealistic if he thinks that government will listen to anything we have to say along the lines he suggests. GDPs have been fighting to save the GDS, using the exact arguments he puts so cogently, since the new contract in 1990 and the fee cut in 1992. We were not listened to then and we will not be listened to now. The deck chairs will undoubtedly continue to be rearranged at an ever more franctic pace, to less and less effect, and to the despair of those of us in general dental practice. Why should GDPs continue to fight to save the GDS, when we have been so consistently ignored, and when all the evidence clearly demonstrates that saving the GDS is the last thing that the Government and the Department of Health actually want? I for one have better uses for my energy, caring for my patients who value a high quality of care, outside the GDS.

\section{Robson}

Oxford

\section{Duty of care}

Sir, - I was interested and saddened to read of the care (or lack of) provided for the patient in case 2 of part 3 on crowns and extra-coronal restorations (BDJ 2002; 192: 257-267) and would like to congratulate the practitioner who produced the results radiographically shown at fig. 11 .

Ignoring the duty of care which the dental hospital had nelected to pursue due to 'the incredible delays over 13 years' I find it rather annoying that the authors feel justified in commenting on the General Dental Service provision in ideal circumstance. They admit that treatment was provided by 176 visits over a nine month period but do not give any report of the time involved for the practitioner in negotiating with the Dental Practice Board, any reference to the Dental Reference Service before or after treatment, any delay in payment by such referral and finally whether the dental practitioner concerned actually made any income, (we are not allowed to talk of profit in such circles) after the laboratory cost. I would strongly endorse the ideal circumstances we would all like but the reality is that such extensive treatment as described is, on a cost per hour basis, a 'loss leader' within the General Dental Service which the academic dental service chooses to ignore.

\section{J. C. Sellar \\ Kendal}

Co-author Mr D. J. Jacobs responds: We thank Mr Sellar for his letter and wish to make the following comments. The main purpose of case 2 was to illustrate the repercussions of poor decision making in treatment planning rather than the specific details of the subsequent care necessary to rescue the case. The matter of resources within the General Dental Service, which the correspondent raises in his letter, is not the issue. We recognise the constraints that the funding system puts on the care in the GDS but this is no defence against bad decision making in the first place. Finally, the article did not seek to draw comparisons of standard of care between primary and secondary care dental services, far from it. In case 1 from the same article most of the poor planning took place in a dental hospital and illustrates how inappropriate decisions result in poor outcomes wherever they are made, regardless of profitability. 